\title{
Cognitive factors related to childbirth and their effect on women's delivery preference: a comparison between a private and public hospital in Tehran
}

\author{
S.G. ChoobMasjedi, ${ }^{1}$ J. Hasani, ${ }^{1}$ M. Khorsandi ${ }^{2}$ and M. Ghobadzadeh ${ }^{3}$
}

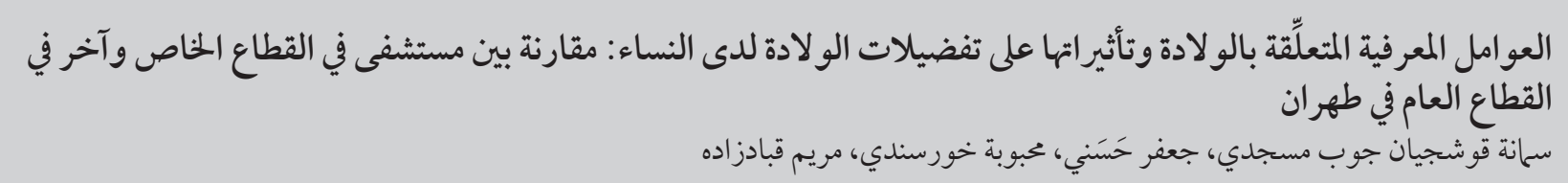

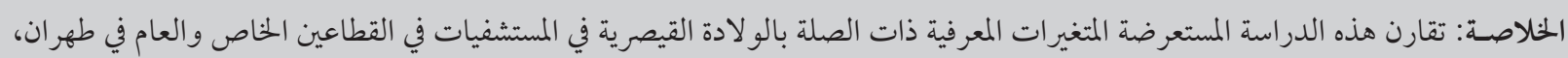

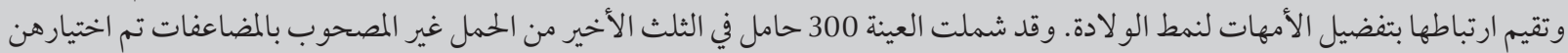

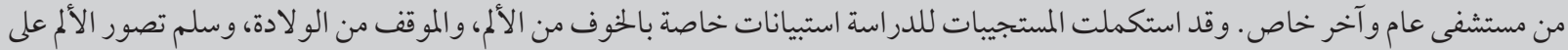

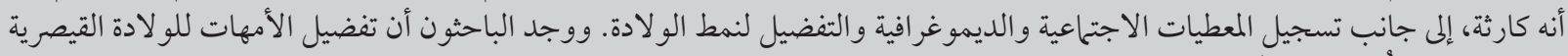

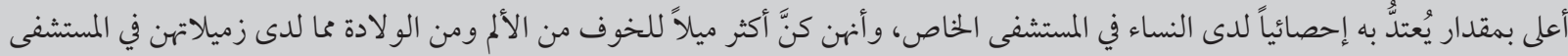

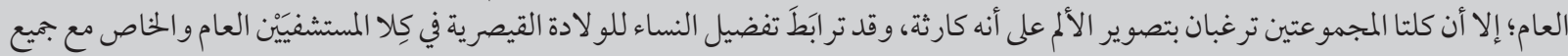

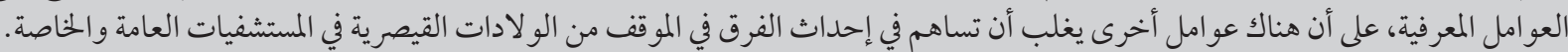

\begin{abstract}
This cross-sectional study compared cognitive-related variables for caesarean delivery in a private and public hospital in Tehran and assessed their association with maternal preference for delivery mode. A sample of 300 pregnant women in their final trimester of uncomplicated pregnancy was recruited from 1 private and 1 public hospital. They completed the Fear of Pain, Childbirth Attitude and the Pain Catastrophizing Scale questionnaires, and their sociodemographic data and delivery preference were recorded. Maternal preference for caesarean delivery was significantly higher in women in the private hospital, and they were significantly more likely to fear pain and childbirth than those in the public hospital; however, both were equally likely to catastrophize in painful situations. Women's preference for caesarean delivery in both hospitals was significantly associated with all the cognitive factors. Other factors are likely to contribute to the difference in caesarean delivery in the private and public hospital.
\end{abstract}

Facteurs cognitifs relatif à l'accouchement et leur effet sur les préférences des femmes en la matière : comparaison entre un hôpital privé et public à Téhéran

RÉSUMÉ La présente étude transversale a comparé les variables liées aux facteurs cognitifs pour une césarienne dans un hôpital privé et public de Téhéran et a évalué leur association avec les préférences des mères pour le mode d'accouchement. Un échantillon de 300 femmes enceintes dans leur dernier trimestre d'une grossesse sans complication a été recruté dans un hôpital privé et un hôpital public. Elles ont rempli les questionnaires Fear of Pain (peur de la douleur), Childbirth Attitude (attitude vis-à-vis de l'accouchement) et Pain Catastrophizing (dramatisation de la douleur). Leurs données sociodémographiques ainsi que leurs préférences en matière d'accouchement ont été enregistrées. Les préférences de mères pour une césarienne étaient bien supérieures chez les femmes consultant à l'hôpital privé, et celles-ci étaient nettement plus susceptibles d'avoir peur de la douleur et de l'accouchement que les femmes consultant à l'hôpital public ; toutefois, les femmes des deux groupes présentaient une probabilité égale de dramatiser les situations douloureuses. Les préférences des femmes pour une césarienne dans les deux hôpitaux étaient significativement associées à l'ensemble des facteurs cognitifs. D'autres facteurs sont susceptibles de contribuer à la différence entre hôpital public et hôpital privé en ce qui concerne la préférence d'un accouchement par césarienne.

${ }^{7}$ Department of Psychology, Tarbiat Moallem University, Tehran, Islamic Republic of Iran. ${ }^{2}$ School of Nursing and Midwifery, Arak University of Medical Sciences, Arak, Islamic Republic of Iran. ${ }^{3}$ School of Public Health, University of Minnesota, Minneapolis, Minnesota, United States of America (Correspondence to M. Ghobadzadeh:ghoba001@umn.edu).

Received: 09/07/11; accepted: 21/11/11 


\section{Introduction}

The caesarean section (CS) rate has increased dramatically over the past 3 decades both in developed [1] and developing countries $[2,3]$. Caesarean delivery greatly improves pregnancy outcomes when clinically indicated but high caesarean delivery rates have raised questions about the health and economic consequences of this practice. CSs are associated with an intrinsic risk of increased severe maternal outcomes compared with vaginal delivery [4-6]. Maternal demographic factors such as age, race, education, marital status, race/ ethnicity and other non-clinical factors like insurance status and institutional factors have been associated with and may increase the caesarean delivery rate [7-15].

Rates of CS vary according to hospital type; private hospitals have higher CS rates than do public one in both in both developed and developing countries [14-16]. Researchers have demonstrated the role of institutional factors such as ownership (private or public) $[17,18]$. In the Islamic Republic of Iran, CS prevalence is almost $40 \%$ in the public sector and $>90 \%$ in some private hospitals [16]. According to the study of Bailit et al. institutional factors and increasing patient demand for elective caesarean delivery can account for the increase in the caesarean birth rate [19].

Cognitive factors have also been implicated in women's requests for CSs and may explain variations in individual CS rates. The majority of women who fear childbirth request an elective CS $[20,21]$; such a request may be to avoid pain. One of the factors related to the fear of pain is pain catastrophizing [22-24]. Pain catastrophizing is defined as an exaggerated negative orientation to painful stimuli and reflects an excessively negative cognitive and emotional orientation toward pain [25]. People with high catastrophizing scores have difficulty suppressing pain-related thoughts and behaviours [26]. Pain catastrophizing is positively associated with the fear of being overwhelmed by labour pain and maternal tendency to avoid the pain [22]. It has been estimated that over $20 \%$ of low-risk pregnancies are complicated by intense fear related to childbirth and $6 \%-10 \%$ of the women describe a fear that is seriously incapacitating [27]. Fear of childbirth has been associated with slower labour and requests for CS [9,28-30].

Recent research suggests the need to analyse women's motives for birth choice $[11,12]$. Most previous studies of CS have focused on the association between rates and institutional type, size, private insurance [15] and physician factors [31] and there have been few studies that examined cognitive factors associated with preference for CS. Therefore, the primary aim of this study was to compare the differences in cognitive-related variables for CS (fear of pain, pain catastrophizing, attitude to childbirth) in private and public hospitals in Tehran, Islamic Republic of Iran. The association between the maternal preference for mode of delivery and cognitive variables was also studied. A better understanding of these factors might help to improve maternity care and to explain increases in caesarean rates. To our knowledge this is the first study ever to compare cognitive factors related to CS.

\section{Methods}

\section{Participants and setting}

This was a cross-sectional comparative study conducted in 2010. Participants were a convenience sample of pregnant women of gestational age 34-38 weeks attending the antenatal care units of 2 hospitals in Tehran: a private hospital (Atieh) and a government-funded hospital (Akbarabadi). In the private hospital women are allowed to request caesarean births without clinical indications but the public institution does not allow elective CS. The public hospital has the lowest CS rate (23\%) and while the figure is $>87 \%$ in the private hospital [32].

Inclusion criteria for the women were: no previous surgical delivery, and uncomplicated current pregnancy with no indication for performing CS. Although previous caesarean delivery is not a necessary medical indication for subsequent caesarean delivery, the notion "Once a caesarean, always a caesarean" still always holds true in the Islamic Republic of Iran. Therefore, we treated previous CS as a medical indication for CS. A woman's previous experience of a delivery type may condition her to opt or expect that kind of birth in subsequent deliveries and it could have influenced the study result.

\section{Ethical considerations}

Ethical approval for the study and the approval for conducting the study in hospitals were obtained from the Ethics Committees of Tarbiat Moallem University and the hospitals' Research Committees in 2010. Women invited to participate were assured that all collected information was confidential. All participants gave written informed consent prior to their participation.

\section{Instruments}

Demographic and obstetric data collected included maternal age, marital status, educational level, reproductive history (parity, gestational age at interview), and preferred mode of delivery for the current pregnancy. The instruments used in this study were:

Fear of Pain Questionnaire (FPQ-III) to assess fears about pain [32]. FPQ-III is a 30-item instrument using a 5-point Likert scale that measures fear about specific situations that would typically produce pain. Total scores range from 30 to 150 . FPQ-III is a well-validated instrument appropriate for use in clinical and non-clinical settings and has a good reliability (Cronbach alpha $=$ $0.80)[33,34]$. 
Pain Catastrophizing Scale (PCS) to assess catastrophic thinking about pain. PCS consists of 13 items rated on a 5-point scale [35]. Participants are instructed to indicate the degree to which they have specified thoughts and feelings when experiencing pain. Three dimensions of PCS are recognized: rumination, magnification and helplessness. These item scores are summed to yield a total score ranging from 0 to 52 [35-37]. Participants were asked to complete the PCS questionnaire in reference to a previous pain event and indicate the degree to which they experienced the 13 thoughts or feelings during the event. Those scoring $>24$ were classified as catastrophizers. Internal consistency was acceptable for the total score $(\alpha=0.92)$.

Childbirth Attitude Questionnaire (CAQ) to assess women's ability to cope with labour and fear of childbirth. CAQ consists of 14 items rated on a 4-point scale. The score ranges from 14 to 56 . A higher score indicates more severe fear of childbirth. This is a validated instrument with good reliability (Cronbach alpha $=0.84)[38]$.

\section{Sample size}

Using a formula for sample size determination for between-groups comparison, at a power of $95 \%$ and a confidence level of $95 \%$, the minimum sample size was 150 women from each hospital. Women were selected consecutively as they attended a scheduled for a prenatal visit at the study hospitals. The questionnaire was administered and completed by trained interviewers.

\section{Statistical analysis}

The data collected were analysed using descriptive and inferential statistics. We employed a between-subjects multivariate analysis of variance (MANOVA) to assess the significance of the differences in means for cognitive variables between the 2 groups. Pearson correlation coefficients were used to examine the association between cognitive factors and maternal preference for caesarean delivery.

Results are presented as means and standard deviations (SD) or frequency percentages. $P$-values and $95 \%$ confidence intervals in multivariate analyses are given; a $P$-value $<0.05$ was considered statistically significant. All analyses were done using SPSS, version 15.

\section{Results}

All 300 women were included in the analyses. We compared the characteristics of the women in the 2 hospitals and compared the 2 hospitals according to cognitive variables and maternal preference for operative delivery.

The participants were all married. The age distribution was similar between groups and the overall mean age was 27.67 (SD 5.86) years. The biggest proportion of women had a high-school diploma (41.3\%), while $23.9 \%$ had 9 years of schooling, $15.9 \%$ had a bachelor degree, $10.3 \%$ had a primary school eduh cation, $5.3 \%$ were illiterate and $3.3 \%$ had a master's degree. Most of the women were nulliparous (55.3\%).

Table 1 presents means and SDs for the demographic and cognitive variables for the 2 groups of women separately. No significant differences were found between the 2 groups with regards to mean age, level of education, gestational age and previous number of pregnancies $(P>0.05)$.

The preferred mode of delivery was elective CS for $47.3 \%$ of the women in the public hospital and $68.7 \%$ in the private hospital, a statistically significant difference $(P<0.05)$. Among nulliparous women, $55.3 \%$ strongly preferred caesarean delivery compared with $44.7 \%$ of multiparous women.

\begin{tabular}{|c|c|c|}
\hline \multicolumn{3}{|c|}{$\begin{array}{l}\text { Table } 1 \text { Demographic characteristics and scores on cognitive variables of the } \\
\text { women by hospital type }\end{array}$} \\
\hline Variable/type of hospital & Mean & SD \\
\hline \multicolumn{3}{|l|}{ Fear of pain } \\
\hline Public & 74.96 & 21.84 \\
\hline Private & 83.90 & 24.07 \\
\hline \multicolumn{3}{|l|}{ Pain catastrophizing } \\
\hline Public & 30.43 & 11.14 \\
\hline Private & 28.14 & 12.42 \\
\hline \multicolumn{3}{|l|}{ Attitude to childbirth } \\
\hline Public & 36.56 & 8.02 \\
\hline Private & 34.18 & 9.07 \\
\hline \multicolumn{3}{|l|}{ Age (years) } \\
\hline Public & 26.62 & 6.56 \\
\hline Private & 28.72 & 4.87 \\
\hline \multicolumn{3}{|l|}{ Years of education } \\
\hline Public & 8.05 & 1.06 \\
\hline Private & 10.98 & 1.09 \\
\hline \multicolumn{3}{|l|}{ Parity } \\
\hline Public & 1.52 & 0.50 \\
\hline Private & 1.58 & 0.49 \\
\hline \multicolumn{3}{|l|}{ Gestational age (weeks) } \\
\hline Public & 34.7 & 1.2 \\
\hline Private & 34.2 & 1.5 \\
\hline
\end{tabular}




\section{Differences in cognitive- related variables between hospitals}

There were no statistically significant differences in the mean scores for the cognitive factors between the women in the private and public hospitals (Table 1). The PCS indicated that, on average, pregnant women in both groups catastrophize during painful situations - mean overall PCS score was 30.43 (SD 11.14) in the women in the public hospital and 28.14 (SD 12.42) in those in the private hospital (Table 1).

Using MANOVA, we examined the mean difference of the 3 cognitive factors (fear of pain, pain catastrophizing, attitude to childbirth) between the women in private hospital and the women in public hospital. Hospital group served as an independent variable, and age, number of pregnancies and education level were considered covariates (Table 2). There were significant differences between the women in private and public hospital with regard to fear of pain $(P=0.001)$ and childbirth attitude $(P=0.017)$ but not for pain catastrophizing $(P=0.094)$. In addition, we conducted pair-wise comparisons of cognitive factors in the women in the private and public hospitals (Table 3). After controlling for confounding factors, the difference between FPQ-III scores for women in private versus public hospitals was statistically significant $(P<0.0001)$ (Table 3$)$, with women in the private hospital displaying greater fear. However, the mean difference between the 2 groups for pain catastrophizing was not statistically significant after adjusting for the effect of other independent variables $(P=0.105)$, with both groups being catastrophizers.
For attitude to childbirth scores, the mean difference between women in the 2 hospitals was statistically significant after adjusting for the effect of other independent variables $(P<0.017)$.

\section{Correlation analyses}

The second objective of the study was to assess the associations between cognitive factors and women's preferences for caesarean delivery. Statistically significant positive correlations were found between maternal fear of pain and maternal preference for operative delivery in the public $(r=0.32, P<0.01)$ and private hospitals $(r=0.43, P<0.01)$ (Table 4 ) indicating that higher scores were associated with a tendency to prefer surgical delivery. There were no significant differences between the 2 groups regarding their pain catastrophizing scores. Nevertheless statistically significant positive correlations were found between the scores and maternal preference for caesarean delivery $(P$ $<0.01$ ) (Table 4). The Pearson correlation test indicated a statistically significant association between attitude to childbirth scores and maternal preference for CS in private hospitals $(r=0.33$, $P<0.01)$ (Table 4).

\section{Discussion}

Our results show that maternal preference for caesarean delivery was significantly higher in the private than public hospital. In addition, women in the private hospital were significantly more likely to fear pain and childbirth than those in the public hospital. However, both were equally likely to catastrophize in painful situations.
Furthermore, women's preference for caesarean delivery in both the private and public hospitals was significantly associated with all the cognitive factors evaluated in the study. Therefore, it may be reasonable to say the difference in the rate of surgical delivery between the public and private hospital is more likely due to the opportunity of women in the private hospital to be involved in decision-making regarding mode of delivery and to have the option of an elective CS.

Several studies have found that the caesarean rate tends to be much higher because of mother's preferred mode of delivery $[11,39,40]$. Jackson and Irvine report that over $38 \%$ of deliveries at a UK hospital were elective CS performed because of maternal preference. The study concluded that maternal request for surgical delivery is a relevant factor for the increasing CS rates [28]. This clearly explains the high CS rates in some regions where women are allowed a role in deciding the mode of delivery. In contrast, in other areas, such as Latin American countries, where women are not allowed such a role and mostly indicate a preference for a vaginal birth, significant differences in preferences between pregnant women in public and private facilities are not generally reported [19]. Potter et al. found that differences in the rates of CS between public and private patients in Brazil were due more to unwanted CSs among private patients than to a difference in preferences regarding type of delivery [14]. In addition, Angeja et al. showed that the higher CS rates in private patients compared with public could not be explained by mother's preference for caesarean delivery [17]. In their study

\begin{tabular}{llcccc}
\hline \multicolumn{5}{l}{ Table 2 Between-subject effects for cognitive variables (fear of pain, pain catastrophizing, and attitude childbirth): MANOVA } \\
\hline Source & Dependant variable & Type III sum of squares & Mean squares & $\boldsymbol{F}$ & $\boldsymbol{P}$-value \\
Hospital & Fear of pain & 6003.2 & 6003.2 & 11.36 & 0.001 \\
& Pain catastrophizing & 392.16 & 392.16 & 2.815 & 0.094 \\
& Attitude to childbirth & 424.83 & 424.83 & 5.78 & 0.017 \\
\hline
\end{tabular}

Degrees offreedom $=1$ for all. 


\begin{tabular}{|c|c|c|c|c|c|c|c|}
\hline \multirow[t]{2}{*}{ Dependent variable } & \multirow[t]{2}{*}{ (I) Hospital } & \multirow[t]{2}{*}{ (J) Hospital } & \multirow{2}{*}{$\begin{array}{c}\text { Mean } \\
\text { difference (I-J) }\end{array}$} & \multirow[t]{2}{*}{ SE } & \multirow[t]{2}{*}{$P$-value ${ }^{\mathrm{a}}$} & \multicolumn{2}{|c|}{$95 \% \mathrm{Cl}^{\mathrm{a}}$} \\
\hline & & & & & & Lower & Upper \\
\hline \multirow{2}{*}{$\begin{array}{l}\text { Fear of pain total } \\
\text { score }\end{array}$} & Public & Private & $-9.510^{*}$ & 2.603 & $<0.0001$ & -14.632 & -4.388 \\
\hline & Private & Public & $9.510^{*}$ & 2.603 & $<0.0001$ & 4.388 & 14.632 \\
\hline \multirow{2}{*}{$\begin{array}{l}\text { Pain catastrophizing } \\
\text { scale total score }\end{array}$} & Public & Private & 2.219 & 1.366 & 0.105 & -0.469 & 4.906 \\
\hline & Private & Public & -2.219 & 1.366 & 0.105 & -4.906 & 0.469 \\
\hline \multirow{2}{*}{$\begin{array}{l}\text { Attitude to childbirth } \\
\text { total score }\end{array}$} & Public & Private & $2.399^{*}$ & 0.992 & 0.016 & 0.446 & 4.352 \\
\hline & Private & Public & $-2.399 *$ & 0.992 & 0.016 & -4.352 & -0.446 \\
\hline
\end{tabular}

Based on estimated marginal means.

${ }^{a}$ Adjustment for multiple comparisons: least significant difference (equivalent to no adjustments).

*Mean difference is significant at $P<0.05$.

$S E=$ standard error of the mean; $\mathrm{Cl}=$ confidence interval for the difference.

of pregnant Chilean women, the vast majority preferred vaginal to caesarean delivery.

Our results also imply that the maternal preference for surgical mode of delivery is sensitive to most cognitive factors in the both hospitals. Psychological issues, such as fear of pain and childbirth-related fear, have been reported to be essential factors behind the request for CS without any medical reason [41]. Studies that examined the maternal reasons for opting for a caesarean delivery found that the most common reason for electing a caesarean is labour pain [42]. Fear of labour pain is strongly associated with the fear of pain in general, and a previous complicated childbirth or inadequate pain relief are the most common reasons for requesting a CS among parous women [43]. In our study, while the women in the private hospital reported greater fear of pain, nevertheless fear of pain was

\begin{tabular}{l}
\hline $\begin{array}{l}\text { Table } 4 \text { Correlation between preference for caesarean delivery and cognitive } \\
\text { factors in the public and private hospital }(\boldsymbol{n}=\mathbf{1 5 0} \text { in both hospitals })\end{array}$ \\
$\begin{array}{l}\text { Preference for caesarean delivery } \\
\text { Public hospital }\end{array}$ \\
$\begin{array}{l}\text { Pear of pain score } \\
\text { Pearson } r\end{array}$ \\
$\begin{array}{l}\text { Attitude to childbirth score } \\
\quad \text { Pearson } r\end{array}$ \\
$\begin{array}{l}\text { Pain catastrophizing score } \\
\quad \text { Pearson } r\end{array}$ \\
\hline
\end{tabular}

${ }^{*} P<0.01$ (2 tailed) $*{ }^{*} P<0.05$ (2 tailed). associated with a greater desire for CS in both groups.

Since there was a positive correlation between the fear of pain and maternal desire for CS in both groups, the difference in the rate of caesarean delivery between the public and private sector may be attributable to the fact that the private sector allows pregnant women to elect for CS. Private hospitals usually tend to medicalize childbirth and obstetricians have been eager to use technology to remove their patient's fear of vaginal delivery. In one study, the most common reason why obstetricians carried out CS on maternal request was the patient's fear and her insistence [44]. Although fear of pain is a strong reason why pregnant women would prefer a CS, concern about pain is usually not a scientific-based reason to request CS. When a pregnant woman is afraid of labour pain, it is not an indication for caesarean delivery; instead it is

an indication for education and specific reasons for the preference should be explored and discussed. An effective way to address the problem is through patient education - providing information on which patients can make informed choices. With education and information the patient will still have a choice, but the number of women requesting elective CS should fall [45]. Fear of labour pain and lack of childbirth education characterize Iranian women's experience of pregnancy and childbirth [16]. Prenatal education classes rarely present information about the birth process, nor do they introduce coping skills concerning labour pain [16]. Furthermore, no pain relief is given during labour and inadequate pain relief might contribute to maternal preference for caesarean delivery to avoid pain [46]. Therefore CS may seem the only option available to avoid the pain of labour for those who can pay for private care. From our analysis, childbirth fear was associated with preference for CS regardless of hospital type. The participants in the public hospital had significantly higher levels of childbirth fear than the private hospital, although CS is not an option that pregnant women can choose for themselves in the public hospital. Our finding is in line with those of Nieminen et al. that showed a significant correlation between childbirth fear and the desire for CS [47]. In view of the fact that the sample in the public hospital 
sector showed lower fear of pain on FPQs, clearly there were other factors than pain alone that were associated with the high childbirth-related fear.

Fear of childbirth may be related to midwifery care as the support of care providers is one of the most pivotal factors in a positive childbirth experience [48]. Higher levels of childbirth fear in the women in the public hospital could well be the result of the women fearing poor quality of delivery care in the hospital. In these circumstances, choice is not necessarily a preference for CS but rather a choice for safety and predictability. When a woman requests a CS because of childbirth-related fear, she should be provided with counselling and appropriate care to help her to address her fears in a supportive manner.

We found no differences between the women in the 2 hospitals for pain catastrophizing. Nevertheless, considering the elevated PCS scores in both groups of women, all tended to catastrophize during painful situations. The score of $>24$ on the PCS for both groups should alert healthcare providers. High labour pain catastrophizing may affect maternal tendency to opt for caesarean delivery but may be a significant predictor of poorer childbirth satisfaction. Research indicates that in a painful situation or anticipation of a painful situation, catastrophizing creates more intense pain and emotional distress [25].

Our study demonstrates the lack of any difference in association between preference for caesarean and cognitive factors in the women in the private and public hospitals. All pregnant women with psychological issues such as fear of pain may show a preference for caesarean delivery but, as the lower rate of CS in the public hospital shows, preference for CSs does not necessarily reflect an indication for caesarean delivery.

Our study has several limitations. The most important limitation was its cross-sectional design; therefore caution must be exercised in the interpretation of the observed associations. In addition, the study examined the women's preference for caesarean delivery with only one item in the questionnaire and did not consider the final decision on mode of delivery. Moreover, our study is based on a small convenience sample of pregnant women in only 1 public and 1 private hospital; thus the sample may not adequately represent the pregnant women population. This makes the generalizability of the results to a wider population uncertain.

Given the high rates of pain fear and its association with CS preference our findings indicate the need for caregivers to provide pregnant women with accurate and realistic information about caesarean indications, labour pain, and ways of coping with pain and emotional distress. In many cases, however, a woman's decision might be more fundamental than just coping with labour pain; it is likely to be about a personal philosophy of labour and expectations of childbirth. To better understand and manage fear associated with pregnancy and childbirth, it would be useful therefore to study women's personal philosophy of labour and childbirth.

\section{Acknowledgements}

Special thanks are given to all the women who participated in the study. We would also like to thank the members of the Scientific Board of the Nursing and Midwifery Department of Arak University of Medical Sciences for their help in running this study. We thank the staff at the 2 study hospitals for their excellent participation and collaboration.

This study was supported by the research centre of Tarbiat Moallem University. The sponsors of the study had no role in study design, data collection, data analysis, data interpretation or writing the report.

\section{References}

1. Leitch CR, Walker J. The rise in CS rate: the same indications but a lower threshold. British Journal of Obstetrics and Gynaecology, 1998, 105:621-626.

2. Betran AP et al. Rates of CS: analysis of global, regional and national estimates. Paediatric and Perinatal Epidemiology, 2007, 21:98-113.

3. Stanton CK, Holtz SA. Levels and trends in caesarean birth in the developing world. Studies in Family Planning, 2006, 37:41-48.

4. McFarlin L. Elective caesarean birth: issues and ethics of an informed decision. Journal of Midwifery \& Women's Health, 2004, 49:421-429.

5. Armson BA. Is planned caesarean childbirth a safe alternative? Canadian Medical Association Journal, 2007, 176:475-476.

6. Visco AG, Viswanathan M, Lohr KN. Caesarean delivery on maternal request: maternal and neonatal outcomes. Obstetrics and Gynecology, 2006, 108:1517-1529.
7. Ventura SJ et al. Births: final data for 1998. National Vital Statistics Reports, 2000, 48:1-100.

8. Donati S, Grandolfo M, Andreozzi S. Do Italian mothers prefer caesarean delivery? Birth (Berkeley, Calif.), 2003, 30:89-93.

9. Penna L, Arulkumaran S. Caesarean section for non-medical reasons. International Journal of Gynaecology and Obstetrics, 2003, 82:399-409.

10. Rydström K et al. Caesarean sections in Sweden 1990-2001. Stockholm, Centre of Epidemiology, National Board of Health and Welfare, 2006.

11. Chu K-H et al. Women's preference for cesarean delivery and differences between Taiwanese women undergoing different modes of delivery. BMC Health Services Research, 2010, 10:138.

12. Angeja AC et al. Chilean women's preference regarding mode of delivery: which do they prefer and why? British Journal of Obstetrics and Gynaecology, 2006, 113:1253-1258. 
13. Laws PJ et al. Australia's mothers and babies 2005. Sydney, Australian Institute of Health and Welfare National Perinatal Statistics Unit, 2007 (Perinatal Statistics Series, No. 20 (http://www.aihw.gov.au/WorkArea/DownloadAsset. aspx?id=6442458959, accessed 27 August 2012).

14. Potter JE et al. Unwanted caesarean sections among public and private patients in Brazil: prospective study. British Medical Journal, 2001, 323:1155-1158.

15. Murray S, Elston M. The promotion of private health insurance and its implications for the social organization of health-care: a case study of private sector obstetrics practice in Chile. Sociology of Health \& Illness, 2005, 27:701-721.

16. Torkzahrani. S. Commentary: Childbirth education in Iran. Journal of Perinatal Education, 2008, 17:51-54.

17. Angeja AC et al. Chilean women's preferences regarding mode of delivery: which do they prefer and why? BJOG, 2006, 113:1253-1258.

18. Villar J et al. Caesarean delivery rates and pregnancy outcomes: the $2005 \mathrm{WHO}$ global survey on maternal and perinatal health in Latin America. Lancet, 2006, 367:1819-1829.

19. Bailit J, Love T, Mercer B. Rising cesarean rates: Are patients sicker? American Journal of Obstetrics and Gynecology, 2004, 191:800-803.

20. Aziken M, Omo-Aghoja L, Okonofua F. Perceptions and attitudes of pregnant women towards cesarean section in urban Nigeria. Acta Obstetricia et Gynecologica Scandinavica, 2007, 86:42-47.

21. Hildingsson I et al. Few women wish to be delivered by caesarean section. BJOG: an International Journal of Obstetrics and Gynaecology, 2002, 109:618-623.

22. Goubert L, Crombez G, Van Damme S. The role of neuroticism, pain catastrophizing and pain-related fear in vigilance to pain: a structural equations approach. Pain, 2004, 107:234-241.

23. Picavet HS, Vlaeyen JWS, Schouten JSAG. Pain catastrophizing and kinesiophobia: predictors of chronic low back pain. American Journal of Epidemiology, 2002, 156:1028-1034.

24. Sullivan MJ, Bishop SR, Pivik J. The pain catastrophizing scale: development and validation. Psychological Assessment, 1995, 4:524-532.

25. Sullivan MJ et al. Theoretical perspectives on the relation between catastrophizing and pain. Clinical Journal of Pain, 2001, 17:52-64.

26. Crombez $\mathrm{G}$ et al. When somatic information threatens, catastrophic thinking enhances attentional interference. Pain, 1998, 75:187-198.

27. Saisto T, Halmesmäki E. Fear of childbirth: a neglected dilemma. Acta Obstetricia et Gynecologica Scandinavica, 2003, 82:201-208.

28. Jackson NV, Irvine LM. The influence of maternal request on the elective caesarean section rate. Journal of Obstetrics \& Gynaecology, 1998, 18:115-119.

29. Sjögren B. Childbirth: expectations, choices and trends. Lancet, 2000, 365:12.

30. Laursen M, Johansn C, Hedegaard M. Fear of childbirth and risk for birth complications in nulliparous women in the Danish Na- tional Birth Cohort. BJOG: an International Journal of Obstetrics \& Gynaecology, 2009, 116(10):1350-1355.

31. Al-Mufti R, McCarthy A, Fisk NM. Obstetricians' personal choice and mode of delivery. Lancet, 1996, 347:544-548.

32. Alavian M. [Up to $90 \%$ of childbirth cases are cesarean in some hospitals]. Iran newspaper, 11 November 2007:6. [In Farsi]

33. McNeil DW, Rainwater AJ. Development of the Fear of Pain Questionnaire (III). Journal of Behavioral Medicine, 1998, 21:389-410.

34. Keogh E et al. Selective attentional bias for pain-related stimuli amongst pain fearful individuals. Pain, 2001, 91:91-100.

35. Sullivan MJL et al. Catastrophizing, pain, and disability in patient with soft-tissue injuries. Pain, 1998, 77:253-260.

36. Sullivan MJL, Bishop SR, Pivik J. The Pain Catastrophizing Scale: development and validation. Psychological Assessment, 1995, 7:524-532.

37. Sullivan MJL, Stanish WD. Psychologically based occupational rehabilitation: the pain-disability prevention program. Clinical Journal of Pain, 2003, 19:97-104.

38. Lowe NK. Maternal confidence for labor: development of the childbirth self-efficacy inventory. Research in Nursing \& Health, 1993, 16:141-149.

39. Sufang $G$ et al. Delivery settings and caesarean section rates in China. Bulletin of the World Health Organization, 2007, 85: 755-62.

40. Dobson R. Caesarean section rate in England and Wales hits 21 per cent. BMJ (Clinical Research Ed.), 2001, 323:951.

41. Halvorsen $\mathrm{L}$ et al. Is there an association between psychological stress and request for caesarean section? Tidsskrift for Den Norske Laegeforening, 2008, 128:1388-1391.

42. Gamble $\mathrm{J}$ et al. A critique of the literature on women's request for cesarean section. Birth (Berkeley, Calif.), 2007, 34(4):331340.

43. Saisto T, Halmesmäki E. Fear of childbirth: a neglected dilemma. Acta Obstetricia et Gynecologica Scandinavica, 2003, 82:201-208.

44. Arikan DC et al. Turkish obstetricians' personal preference for mode of delivery and attitude toward cesarean delivery on maternal request. Archives of Gynecology and Obstetrics, 2011, 284(3):543-549.

45. Montgomery L. Patient education is way to influence maternal requests for caesarean section. BMJ (Clinical Research Ed.), 1999, 319:190.

46. Khorsandi, Mahboobeh. Iranian version of the Childbirth Self-efficacy Inventory. Journal of Clinical Nursing, 2008, 17(21):2846-2855.

47. Nieminen K, Stephansson O, Ryding EL. Women's fear of childbirth and preference for caesarean section - a cross-sectional study at various stages of pregnancy in Sweden. Acta Obstetricia et Gynecologica, 2009, 88:807-813.

48. Hodnett ED et al. Continuous support for women during childbirth. The Cochrane Database of Systematic Reviews 2007 Jul 18;(3):CD003766. 